\title{
Melão (Cucumis melo L.): interrelações entre adubação, nutrição mineral e produção
}

\begin{abstract}
A quantidade e a proporcionalidade dos nutrientes absorvidos pelas plantas são funções de características intrínsecas do vegetal, como, também, dos fatores externos que condicionam o processo. Em uma espécie, a capacidade em retirar os nutrientes do solo e as quantidades requeridas variam não só com a cultivar, mas também com o grau de competição existente. Variações nos fatores ambientais como temperatura e umidade do solo podem afetar o conteúdo de nutrientes minerais nas folhas consideravelmente. Esses fatores influenciam tanto a disponibilidade dos nutrientes como a absorção destes pelas raízes e, consequentemente, o crescimento da parte aérea. Por outro lado, o acúmulo e a distribuição, dos nutrientes minerais na planta dependem de seu estádio de desenvolvimento. Avaliou-se a produção de massa seca, os teores de nitrogênio, fósforo, potássio, cálcio, magnésio e enxofre na parte aérea da cultura na planta dependem de seu estádio de desenvolvimento. Avaliou-se a produção de massa seca, os teores de nitrogênio, fósforo, potássio, cálcio, magnésio e enxofre na parte aérea da cultura do melão em função de cada tratamento. O delineamento experimental utilizado foi em blocos casualizados, com cinco repetições e três tratamentos, trat 1: NPK 50-25-25; trat. 2: NPK 10$28-20$ e trat. 3: NPK 3-12-6. Foi utilizada a cultivar híbrida Sunrise, semeada em flooting e posteriormente transplantada para covas em leiras da casa de vegetação, onde já havia sido realizada
previamente adubação e correção baseadas em análise do solo. A irrigação foi realizada por gotejamento, e aos 25 dias após o transplantio foi feito o tutoramento das plantas. A colheita foi previamente adubação e correção baseadas em análise do solo. A irrigação foi realizada por gotejamento, e aos 25 dias após o transplantio foi feito o tutoramento das plantas. A colheita foi realizada progressivamente, de acordo com a maturaça com NPK BIOATIVO (3-12-6) influenciou significativamente $(P<0,05)$ os teores de $S$ e $\mathrm{Mn}$, revelando os maiores teores foliares, com 3,50 g Kg -1 e $255,65 \mathrm{mg} \mathrm{Kg}-1$ respectivamente. $\mathrm{Os}$ tratamentos não influenciaram significativamente nos teores foliares de $\mathrm{N}, \mathrm{P}, \mathrm{K}, \mathrm{Ca}$ e $\mathrm{Mg}$ do meloeiro, apenas quanto ao teor de $\mathrm{S}$.
\end{abstract}

Palavras-chave: Adubação; Massa Seca; Teor Foliar; Cucumis melo.

\section{Melon (Cucumis melo L.): interrelations between fertilization, mineral nutrition and production}

\begin{abstract}
The quantity and proportionality of nutrients absorbed by plants are functions of inherent characteristics of plant, as well as the external factors that influence the process. In a species, the ability to withdraw the nutrients in the soil and the quantities required vary not only to grow, but also with the degree of competition exists. Variations in environmental factors as temperature and soil moisture can affect the content of nutrients in the leaves considerably. These factors influence both the availability of nutrients such as the absorption by the roots and thus the growth of shoots. Moreover, the accumulation and distribution of nutrients in the plant depend on its stage of development. Was evaluated the dry mass production, the levels of leaf nitrogen, phosphorus, potassium, calcium, magnesium and sulfur in the cultivation of melons in each treatment. The experimental design was a randomized blocks, with five repetitions and three treatments, trat 1 : NPK 50-25-25; trat. 2: NPK 10-28-20 and trat. 3: NPK 3-12-6. It was used to cultivate hybrid Sunrise, sown in flooting and then transplanted to the leiras holes in a greenhouse, which had been held previously and correction fertilization based on soil analysis. The drip irrigation was performed, and 25 days after transplanting was done tutoramento the plant. The harvest was done gradually, according to the maturation of fruits, what happened to approximately 60 days after transplanting. The average observed for production of dry mass of the shoot, were higher in treatments $2(21.87 \mathrm{~g}$ plant-1). For the leaf levels of $\mathrm{N}, \mathrm{P}, \mathrm{K}, \mathrm{Ca}$ and $\mathrm{Mg}$ of the melon, there was no significant effect of the treatments. Treatment 3 with NPK BIOATIVO $(3-12-6)$ influenced significantly $(P<0.05)$ the levels of $S$ and $\mathrm{Mn}$, showing the greatest levels leaf, with $3.50 \mathrm{~g} \mathrm{~kg}-1$ and $255.65 \mathrm{mg} \mathrm{kg} \mathrm{-1} \mathrm{respectively.} \mathrm{The} \mathrm{treatments} \mathrm{did} \mathrm{not} \mathrm{influence} \mathrm{significantly} \mathrm{in} \mathrm{the} \mathrm{leaf} \mathrm{levels} \mathrm{of} \mathrm{N}, \mathrm{P}, \mathrm{K}$, $\mathrm{Ca}$ and $\mathrm{Mg}$ of melon, just as the contents of $\mathrm{S}$.
\end{abstract}

Keywords: Fertilization; Dry Mass; Leaf Content; Cucumis melo.

Brenda Rocha Guimarães (D)

Universidade Federal Rural da Amazônia, Brasil http://lattes.cnpq.br/1227316025441394 http://orcid.org/0000-0002-6374-3069 guimaraes.brenda@hotmail.com

\section{Ana Regina da Rocha Araujo (it}

Universidade Federal Rural da Amazônia, Brasil http://lattes.cnpq.br/1331240613899248 http://orcid.org/0000-0002-6037-6582 ana.araujo@ufra.edu.br

\section{Jessivaldo Rodrigues Galvão (it)}

Universidade Federal Rural da Amazônia, Brasil http://lattes.cnpq.br/0013591065769741 http://orcid.org/0000-0003-4242-6555

jessigalvao50@gmail.com

\author{
Mauro Junior Borges Pacheco (D) \\ Universidade Federal Rural da Amazônia, Brasil \\ http://lattes.cnpq.br/0756046215703468 \\ http://orcid.org/0000-0001-6024-7054 \\ mauro.jr720@gmail.com \\ Sérgio Brazão e Silva (iD) \\ Universidade Federal Rural da Amazônia, Brasil \\ http://lattes.cnpq.br/8637550987254599 \\ http://orcid.org/0000-0002-8586-9789 \\ segio.brazao@ufra.edu.br \\ Luis Felipe Conceição Tavares de Assis \\ Universidade Federal Rural da Amazônia, Brasil \\ http://lattes.cnpq.br/2451308405569394 \\ http://orcid.org/0000-0001-5811-915X \\ Izinho1998@gmail.com
}

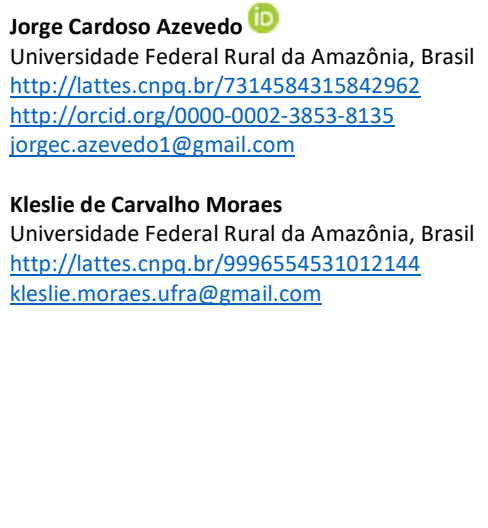

Jorge Cardoso Azevedo (iD 5842962 orgec.azevedo1@gmail.com

Kleslie de Carvalho Moraes

(a) da Amazônia, Brasil

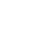

\author{
Referencing this: \\ GUIMARÃES, B. R.; ARAUJO, A. R. R.; GALVÃO, J. R.; PACHECO, M. J. B.; \\ SILVA, S. B.; ASSIS, L. F. C. T.; AZEVEDO, J. C.; MORAES, K. C.. Melão \\ (Cucumis melo L.): interrelações entre adubação, nutrição mineral e \\ produção. Revista Ibero Americana de Ciências Ambientais, v.11, n.1, \\ p.391-399, 2020. DOI: http://doi.org/10.6008/CBPC2179- \\ $\underline{6858.2020 .001 .0035}$
}




\section{INTRODUÇÃO}

A absorção de nutrientes varia com a espécie e, dentro desta, com a cultivar. Maia et al. (2005) se tem reconhecido que espécies de plantas podem diferir quantitativa e qualitativamente quanto ao requerimento de nutrientes minerais. As plantas superiores possuem, em média, $5 \%$ de nutrientes minerais na matéria seca, porém são grandes as diferenças entre espécies, e as quantidades totais exigidas por uma cultura dependem da produtividade. Por outro lado, a absorção de nutrientes é diferente, de acordo com a fase de desenvolvimento da planta, intensificando-se com o florescimento, a formação e o crescimento dos frutos (SILVA JUNIOR et al., 2006).

Os nutrientes minerais desempenham diversas funções nas plantas, determinando ou influenciando diversos processos metabólicos e fisiológicos. A produção fica comprometida em áreas onde existe desequilíbrio de nutrientes, que é acentuado pelos cultivos sucessivos e adubações pesadas. A adubação equilibrada é a chave para a utilização eficiente de fertilizantes e obtenção de rendimentos máximos de melão, em bases sustentáveis (SILVA et al., 2003). Fatores internos e externos influenciam a absorção de nutrientes pelo meloeiro. Entre os internos, pode-se citar o genótipo cultivado e entre os externos, merece atenção as condições climáticas (CRISÓSTOMO et al., 2002).

Entretanto, a quantidade e a proporcionalidade dos nutrientes absorvidos pelas plantas são funções de características intrínsecas do vegetal, como, também, dos fatores externos que condicionam o processo. Numa espécie, a capacidade em retirar os nutrientes do solo e as quantidades requeridas variam não só com a cultivar, mas também com o grau de competição existente. Variações nos fatores ambientais como temperatura e umidade do solo podem afetar o conteúdo de nutrientes minerais nas folhas consideravelmente. Esses fatores influenciam tanto a disponibilidade dos nutrientes como a absorção destes pelas raízes e, consequentemente, o crescimento da parte aérea. Por outro lado, o acúmulo e a distribuição, dos nutrientes minerais na planta dependem de seu estádio de desenvolvimento (MARSCHNER, 1995; GOTO et al., 2001, citados por GRANGEIRO et al., 2004). Diante da carência de resultados de pesquisa para este fim, este trabalho se propôs avaliar a produção de massa secada parte aérea e os teores foliares de nitrogênio, fósforo, potássio, cálcio, magnésio, enxofre, sódio, cobre manganês, ferro e zinco da cultura do melão cultivado em casa de vegetação.

\section{MATERIAIS E MÉTODOS}

No período de Janeiro à Abril de 2007, o experimento foi desenvolvido em casa de vegetação do tipo arco, com $15 \mathrm{~m} \times 6 \mathrm{~m}$, pé-direito de $2,8 \mathrm{~m}$, laterais, frente e fundo desprotegidos, coberta com filme transparente de polietileno de $150 \mu$ de espessura localizada no Instituto de Ciências Agrárias (ICA), pertencente à Universidade Federal Rural da Amazônia (UFRA), em Belém/PA (Figura 12).

Segundo a classificação de Köppen, o clima da região é do tipo Afi, que se caracteriza por apresentar pluviosidade anual superior a $2000 \mathrm{~mm}$, com um regime de chuvas durante praticamente todo o ano e totais mensais iguais ou superiores a $60 \mathrm{~mm}$. A média das temperaturas máximas é de $31,4^{\circ} \mathrm{C}$ e das mínimas $22,4^{\circ}$ 
C. O total de horas de insolação por ano fica em torno de 2.338 e a umidade relativa do ar, em média, é de $84 \%$ (BASTOS et al., 2001).

O experimento foi instalado em casa de vegetação de uma área em que o solo é classificado como Latossolo Amarelo (VIEIRA, 1983). Para caracterização do solo antes da instalação do experimento, inicialmente foram coletadas 10 amostras simples de solo para composição de uma amostra composta, nas profundidades de 0 a $20 \mathrm{~cm}$ e de 20 a $40 \mathrm{~cm}$, com trado tipo 'Sonda'.

As amostras de solo foram colocadas em sacos de polietileno e encaminhadas para análise no laboratório do ICA / UFRA, sendo secas ao ar, após o que, foram destorroadas e peneiradas à malha de $2 \mathrm{~mm}$ de diâmetro. Em seguida, no laboratório foram determinados pH $\left(\mathrm{H}_{2} \mathrm{O}\right.$ e $\left.\mathrm{KCl}\right)$, matéria orgânica, $\mathrm{C}$ orgânico, bases trocáveis ( $\mathrm{K}, \mathrm{Ca}, \mathrm{Mg})$, acidez potencial $(\mathrm{H}+\mathrm{Al})$, Al trocável e $\mathrm{P}$ disponível do solo. Todas as determinações foram realizadas de acordo com a metodologia convencional da Embrapa (1997), exceto o $\mathrm{N}$ total que foi estimado em $50 \mathrm{~kg} \mathrm{ha}^{-1}$ conforme Silva (2003). O resultado da análise química do solo está disposto na Tabela 1.

Tabela 1: Características químicas do solo antes da implantação do experimento nas profundidades de 0-20 e de 20-40 $\mathrm{cm}$.

\begin{tabular}{|c|c|c|c|c|c|c|c|c|c|c|}
\hline Prof. & $\mathrm{pH}$ água & $\mathrm{pH}$ & $\mathrm{P}$ (disponivel) & $\mathrm{K}$ & $\mathrm{Ca}$ & $\mathrm{Mg}$ & $\mathrm{Al}_{\text {(trocável) }}$ & $(\mathrm{H}+\mathrm{Al})$ & $\mathrm{MO}$ & Corg \\
\hline $\mathrm{cm}$ & & & $\mathrm{mg} \mathrm{dm} \mathrm{m}^{-3}$ & \multicolumn{5}{|c|}{ 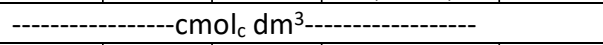 } & \multicolumn{2}{|c|}{----------g kg-1 --------- } \\
\hline $0-20$ & 5,5 & 5,0 & 393,61 & 0,44 & 3,20 & 1,10 & 0,09 & 3,63 & 20,00 & 11,60 \\
\hline $20-40$ & 4,8 & 4,4 & 116,38 & 0,19 & 1,75 & 0,66 & 0,26 & 3,92 & 11,94 & 6,93 \\
\hline
\end{tabular}

Baseada na análise química do solo foi realizada adubação de correção seguindo a recomendação para a cultura do melão proposta por Silva (2003); além de cálculo da necessidade de calagem se utilizando o método da neutralização de alumínio. Em sistema de flooting instalado em casa de vegetação tipo arco, com $15 \mathrm{~m} \times 6 \mathrm{~m}$, pé-direito de 2,8 $\mathrm{m}$, laterais, frente e fundo desprotegidos, coberta com filme transparente de polietileno de $150 \mu$, foram dispostos copos plásticos de $200 \mathrm{ml}$ contendo composto orgânico como substrato (capim, folhas, caroço de açaí, dejetos de pato, esterco bovino), e 2 sementes de melão dá para cultivar híbrida Sunrise. O substrato utilizado foi analisado quimicamente (Tabela 2). Na casa de vegetação, foi realizada calagem com calcário dolomítico (PRNT 80\%), utilizando-se $33 \mathrm{~g} / \mathrm{m}^{2}, 15$ dias antes do transplantio.

Tabela 2: Características químicas do composto orgânico utilizado no experimento.

\begin{tabular}{|c|c|c|c|c|c|c|c|c|c|}
\hline $\mathrm{pH}_{\text {água }}$ & $\mathrm{pH} \quad \mathrm{KCl}$ & $\mathrm{P}$ (disponivel) & $\mathrm{K}$ & $\mathrm{Ca}$ & $\mathrm{Mg}$ & $\mathrm{Al}$ (trocável) & $(\mathrm{H}+\mathrm{Al})$ & $\mathrm{MO}$ & Corg \\
\hline & & $\mathrm{mg} \mathrm{dm} \mathrm{m}^{-3}$ & \multicolumn{5}{|c|}{ 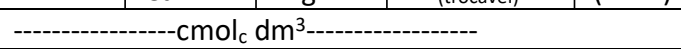 } & \multicolumn{2}{|c|}{ 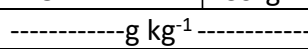 } \\
\hline 7,1 & 6,5 & 1985,00 & 3,54 & 7,10 & 4,82 & 0,01 & 3,66 & 185,56 & 107,63 \\
\hline 4,8 & 4,4 & 116,38 & 0,19 & 1,75 & 0,66 & 0,26 & 3,92 & 11,94 & 6,93 \\
\hline
\end{tabular}

O transplantio para covas, previamente adubadas, localizadas em leiras da casa de vegetação, foi realizado quando as mudas apresentavam a primeira folha definitiva, aos 10 dias após o semeio. 0 espaçamento adotado foi de 1,0 m entre leiras e 0,5 m entre plantas. A irrigação foi realizada por gotejamento, e aos 25 dias após o transplantio foi feito o tutoramento das plantas com fitilhos plásticos presos a arames localizados a $3 \mathrm{~m}$ de altura do solo. Foi conduzida uma planta por cova e realizou-se a poda de todos os ramos laterais até a décima folha. $O$ amarrio das plantas, bem como o controle de ervas daninhas 
foi feito sempre que necessário.

A colheita foi realizada progressivamente, de acordo com a maturação dos frutos, o que aconteceu aproximadamente aos 60 dias após o transplantio. Foram adotados 3 tratamentos, Trat. A: NPK 24-12-12 (50, 25 e $25 \mathrm{Kg} / \mathrm{ha}$ ); Trat. B: NPK 10-28-20 e Trat. C: Bioativo NPK 3-12-6. A formulação do tratamento A foi baseada nos resultados da análise de solo amostrado, segundo Silva (2003) para a cultura do melão (50, 25 e $25 \mathrm{Kg} / \mathrm{ha}$ ). O tratamento B é uma formulação comercial mineral (NPK 10-28-20) de uso tradicional por produtores locais, e o tratamento C é uma formulação comercial organomineral (Bioativo NPK 3-12-6).

A quantidade de adubo por cova no tratamento A definida pela formulação 24-12-12 (50, 25 e $25 \mathrm{Kg} /$ ha), foi de $21,23 \mathrm{~g} /$ cova, tendo como fontes, ureia (para nitrogênio), superfosfato triplo (para fósforo) e cloreto de potássio (para potássio). No tratamento B, foi adotada a formulação de uso comercial 10-28-20, sendo aplicados $12,22 \mathrm{~g} /$ cova com as mesmas fontes fertilizantes usadas no tratamento $A$.

No tratamento $\mathrm{C}$, adotou-se a mesma quantidade para o adubo organomineral calculada para a formulação 10-28-20. Esta metodologia foi adotada em função da equivalência desta formulação (Bioativo NPK 3-12-6) à formulação de uso comercial (NPK 10-28-20), uma vez que o Bioativo NPK 3-12-6 apresenta resultados agronômicos referentes à produtividade, equivalentes aos fertilizantes químicos minerais, com aproveitamento pelas plantas de $100 \%$ dos nutrientes, uma vez que os microrganismos presentes no Bioativo continuam ativos no solo por pelo menos 6 meses, permitindo assim, maior aproveitamento do fósforo; enquanto que as formulações de correções químicas como o NPK 10-28-20 entre outras, tem aproveitamento de fósforo pelas plantas variando de 5 a 30\% no máximo, e de 20 a 50\% de nitrogênio e potássio, conforme dados do IFB Biotecnologia (2006).

Na parte aérea da planta foram realizadas determinações de Nitrogênio $(N)$, Fósforo $(P)$, Potássio $(K)$, Cálcio (Ca), Magnésio (Mg), Enxofre (S), Sódio (Na), Cobre (Cu), Ferro (Fe), Manganês (Mn) e Zinco (Zn). Todas as determinações químicas dos tecidos vegetais seguiram metodologia descrita por Malavolta et al. (1997). $\mathrm{O} \mathrm{N}$ foi determinado pelo método de Kjeldhal, os elementos $\mathrm{P}, \mathrm{K}, \mathrm{Ca}, \mathrm{Mg}, \mathrm{S}, \mathrm{Na}, \mathrm{Cu}, \mathrm{Fe}, \mathrm{Mn}$ e $\mathrm{Zn}$ foram determinados através de digestão nítrico-perclórica 2:1. Sendo o P obtido por coloração com molibdato de amônia e o S por turbidimetria, ambos em espectrofotômetro. Os valores de $\mathrm{K}, \mathrm{Ca}, \mathrm{Mg}, \mathrm{Na}, \mathrm{Cu}, \mathrm{Fe}, \mathrm{Mn}$ e $\mathrm{Zn}$ foram obtidos em espectrofotômetro de absorção atômica.

Utilizou-se o delineamento em blocos ao acaso com 3 tratamentos, em cinco repetições, perfazendo um total de 15 parcelas experimentais, sendo que cada repetição foi constituída por 10 plantas. Os dados referentes às variáveis analisadas foram submetidos à análise de variância, e suas médias foram comparadas pelo teste de Duncan a 5\%, realizados pelo programa estatístico SAEG 8.0.

\section{RESULTADOS E DISCUSSÃO}

A parte vegetativa da planta (rama) contribuiu com mais de $58 \%$ para o acúmulo de matéria seca na parte aérea total (Figura 2). Em ensaios semelhantes, entretanto, utilizando outras cultivares, Prata (1999), Lima (2001) e Duarte (2002) citados por Silva Junior (2006), encontraram que a maior parte da matéria seca acumulada na parte aérea das plantas era proveniente dos frutos. 
A quantidade de massa seca da parte aérea do meloeiro por tratamento não sofreu influência significativa dos tratamentos avaliados. Os dados de quantidade de massa seca da parte aérea do meloeiro apontam uma semelhança entre as fontes de adubação NPK 10-28-20 (Tratamento B) e NPK 3-12-6 (Tratamento C), estando a formulação adquirida após análise de solo NPK 50-25-25 (trat. A), apresentando um comportamento desuniforme quando relacionada aos demais tratamentos (Figura 1).

O tratamento B (NPK 10-28-20), apresentou as maiores médias com relação ao acúmulo de massa seca na parte aérea das plantas de melão, com $21,87 \mathrm{~g} \mathrm{planta}^{-1}$, seguido dos tratamentos A (NPK 50-25-25) e C (NPK 3-12-6), respectivamente com 19,89 $\mathrm{g}_{\text {planta }}{ }^{-1}$ e 14,10 g planta-1. Tais valores estão abaixo dos encontrados por Sousa et al. (2005), onde a matéria seca do meloeiro foi significativamente influenciada ( $P$ $<0,01)$ pelas doses de Nitrogênio $(\mathrm{N})$, de potássio $\left(\mathrm{K}_{2} \mathrm{O}\right)$ e pela interação $\left(\mathrm{N} \times \mathrm{K}_{2} \mathrm{O}\right)$. O maior valor médio de matéria seca do meloeiro (g planta ${ }^{-1}$ ) obtido pelos autores, aconteceu com a aplicação de $100 \mathrm{~kg} \mathrm{ha}^{-1}$ de N e

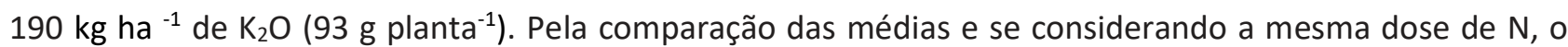
máximo valor de matéria seca diferiu apenas do valor obtido com a combinação de $100 \mathrm{~kg} \mathrm{ha}^{-1} \mathrm{de} \mathrm{N}$ com $100 \mathrm{~kg} \mathrm{ha}^{-1} \mathrm{de}_{2} \mathrm{O}$.

Com a aplicação da menor dose de potássio $\left(100 \mathrm{~kg} \mathrm{ha}^{-1}\right.$ de $\left.\mathrm{K}_{2} \mathrm{O}\right)$, estes autores observaram que o acúmulo de matéria seca aumentou com as doses de nitrogênio; no entanto, somente o valor obtido com a dose de $100 \mathrm{~kg} \mathrm{ha}^{-1}$ de $\mathrm{N}\left(64,74 \mathrm{~g}_{\text {planta }}{ }^{-1}\right)$ diferiu das demais. Esta tendência não foi verificada quando as doses de potássio foram aumentadas para 280 e $370 \mathrm{~kg} \mathrm{ha}^{-1}$ de $\mathrm{K}_{2} \mathrm{O}$, cuja redução na matéria seca ocorreu com o aumento das dosagens de nitrogênio aplicadas, evidenciando que a produção de matéria seca pelo meloeiro tende a reduzir com a elevação das doses de nitrogênio e de potássio.

A desuniformidade dos dados de massa seca da parte aérea nos tratamentos; observada principalmente no tratamento A (NPK 50-25-25); pode ser explicado pelo aparecimento de antracnose (Colletotrichum gloeosporioides [Penz.] Sacc.) no experimento (Tabela 3). Muitas doenças em cultivos protegidos tendem a se tornar mais severas, quando comparadas ao cultivo convencional, pois além dos fatores ambientais mais favoráveis, também deve-se considerar o estado nutricional das plantas, as condições de irrigação, a maior densidade de plantas e o monocultivo, os quais propiciam condições mais favoráveis aos patógenos (VIDA et al., 2004).

Predisposição às doenças ocorre com as plantas em estufa devido às técnicas utilizadas com a finalidade de oferecer-Ihes condições nutricionais para expressarem seu máximo potencial produtivo (VIDA et al., 2004). Além disso, o maior crescimento vegetativo das plantas associado à maior densidade de plantio propicia condições microclimáticas na estufa, tais como menor luminosidade, redução dos ventos, maior tempo de permanência de água livre na superfície foliar e no solo, proporcionando condições mais favoráveis a muitos patógenos (VIDA et al., 2004).

O ambiente na estufa geralmente é mais favorável ao crescimento e produção das plantas. No entanto, mudanças em determinados fatores do ambiente, principalmente nas variáveis climáticas e nutricionais, podem causar mudanças na fisiologia e/ou anatomia das plantas podendo torná-las mais predispostas à infecção por patógenos. Desta forma, o ideal é manejar a estufa de modo a propiciar um 
ambiente conducivo para a produtividade da cultura e supressivo, de alguma forma, para a atividade dos patógenos (VIDA et al., 2004). O compromisso é manter um ambiente próximo do ótimo para a produção e evitar o ótimo para a infecção de um determinado patógeno importante para a cultura (VIDA et al., 2004).

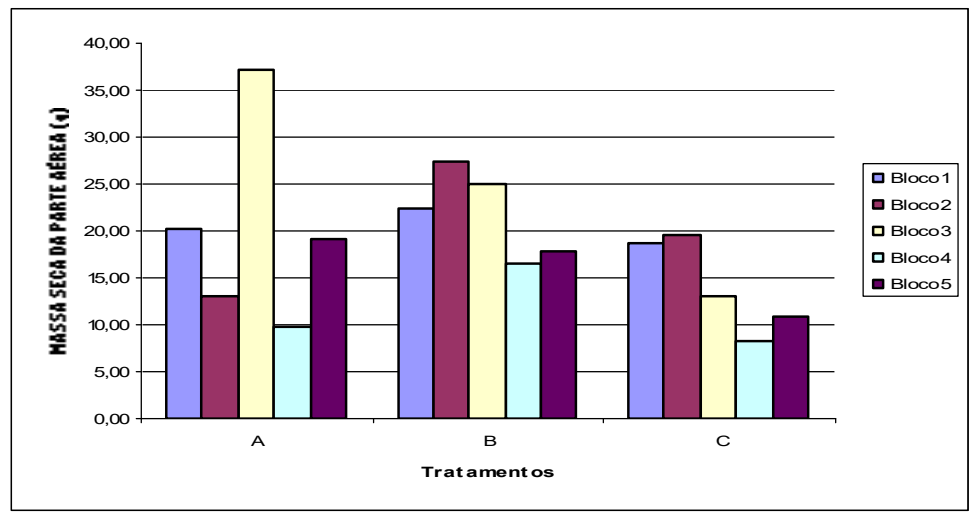

Figura 1: Quantidade de massa seca da parte aérea do meloeiro por tratamento ( $A=$ NPK 50-25-25, $B=$ NPK 10-28-20 e C= NPK 3-12-6).

A formulação gerada após caracterização do solo (A), a formulação comercial 10-28-20 (B) e a adubação organomineral Bioativo (C), apresentaram comportamento estatístico semelhante quanto aos teores de nitrogênio, fósforo e potássio na parte aérea do meloeiro. Na parte aérea da planta, o fósforo obteve sempre os menores teores diante das fontes distintas de adubação, e o potássio revelou para este experimento, os maiores teores em $\mathrm{g} / \mathrm{kg}$ de massa seca de parte aérea de melão (Figura 2 ).
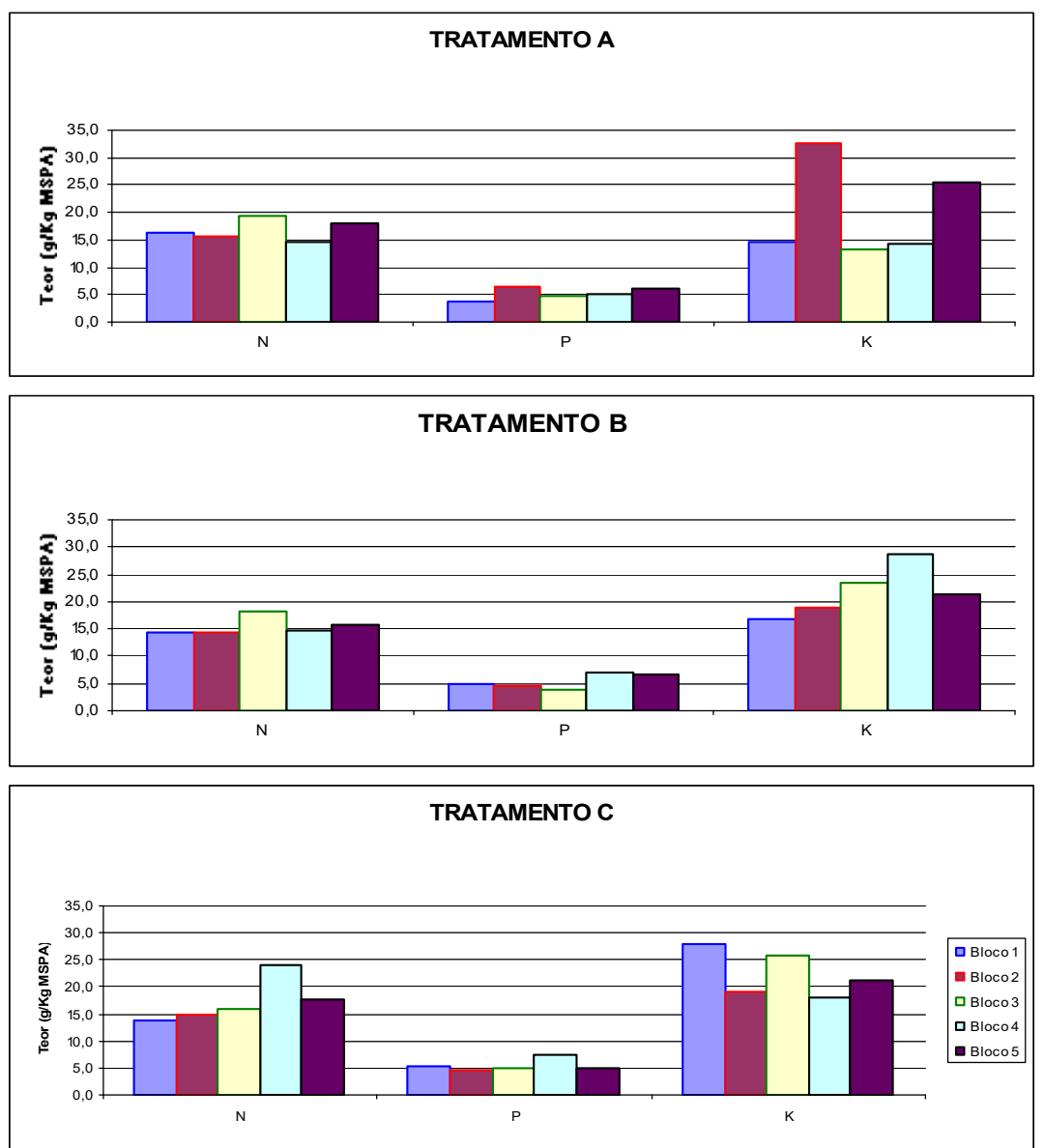

Figura 2: Teores de N, P e K na parte aérea do meloeiro por tratamento. ( $\mathrm{A}$ - formulação gerada após caracterização do solo; B - formulação comercial 10-28-20; C - adubação organomineral Bioativo). 
Os teores extraídos para o potássio; foram em média, maiores no tratamento C apresentando 22,48 $\mathrm{g} / \mathrm{kg}$ de massa seca de parte aérea de melão, seguido dos tratamentos B e $\mathrm{A}$, com 21,76 e 20,01 g/kg de massa seca de parte aérea de melão respectivamente. Para nitrogênio, seguiu-se o mesmo comportamento do potássio, tendo o tratamento $C$ apresentado os maiores valores médios seguido dos tratamentos $A$ e $B$ $(17,22 ; 16,78$ e 15,46 g/kg de massa seca de parte aérea de melão respectivamente). A planta extraiu teores menores de fósforo quando comparado aos teores de potássio e ao nitrogênio, tendo os tratamentos $\mathrm{C}, \mathrm{B}$ e A apresentado os seguintes valores médios respectivamente, 5,40;5,34 e 5,21 g/ $/ \mathrm{g}$ de massa seca de parte aérea de melão.

Na Tabela 3, nota-se que não houve diferença significativa entre os resultados médios dos teores de nitrogênio, fósforo e potássio em relação aos tratamentos utilizados. Entretanto, nota-se que os resultados médios de teores de $\mathrm{N}$ encontrados em todos os tratamentos foram inferiores aos relatados por Fernandes et al. (2003), utilizando diferentes doses de $\mathrm{N}$ e K; estando também, abaixo das médias de teores considerados adequados por Belfort et al. (1986), utilizando variedades do grupo inodorus.

As médias de teores de $\mathrm{N}$ em g Kg de matéria seca ${ }^{-1}$ encontradas por Duenhas et al. (2004) nos tecidos vegetais aos 30, 45 e 60 dias após a emergência de plantas de melão, também foram superiores aos encontrados neste trabalho. Os teores de $\mathrm{P}$ e $\mathrm{K}$ encontrados na parte aérea do meloeiro para todos os tratamentos foi superior aos encontrados em folhas de meloeiro por Fernandes et al. (2003) e Duenhas et al. (2004).

Tabela 3: Resultados analíticos médios dos teores de macronutrientes na parte aérea de plantas de melão, em função de diferentes tipos de adubação.

\begin{tabular}{|c|c|c|c|c|c|c|}
\hline Tratamentos & $\mathrm{N}$ & $\mathrm{P}$ & $\mathrm{K}$ & $\mathrm{Ca}$ & $\mathrm{Mg}$ & $\mathrm{S}$ \\
\hline & \multicolumn{6}{|c|}{-------------------------------- $\mathrm{g} \mathrm{kg}^{-1}$-------------------------------------- } \\
\hline NPK (50-25-25) & $16,78 \mathrm{a}$ & $5,21 a$ & $20,01 \mathrm{a}$ & $57,02 a$ & $13,38 a$ & $1,96 \mathrm{~b}$ \\
\hline NPK (10-28-20) & $15,46 \mathrm{a}$ & $5,34 a$ & $21,76 \mathrm{a}$ & $55,72 a$ & $12,83 \mathrm{a}$ & $2,74 a b$ \\
\hline NPK (3-12-6) & $17,22 \mathrm{a}$ & $5,40 \mathrm{a}$ & $22,48 a$ & $54,50 \mathrm{a}$ & 13,37 a & $3,50 \mathrm{a}$ \\
\hline
\end{tabular}

As médias seguidas pela mesma letra minúscula na coluna não apresentam diferenças significativas ao nível de 5\% pelo Teste de Duncan. Considerando-se o cálcio e o magnésio isoladamente, vê-se que a planta extraiu os maiores teores desses elementos (Figura 18). Tal observação serve para confirmar a hipótese de que o cálcio e o magnésio são nutrientes de difícil redistribuição na planta, acumulando-se nas folhas que é o final da via xilemática (SILVA JUNIOR, 2006).

Os resultados de Ca encontrados neste trabalho estão próximos aos teores encontrados por Fernandes et al. (2003) trabalhando com híbrido Bônus II, concordando com teores considerados adequados por Reuter et al. (1986) citados pelos mesmos, utilizando variedades do grupo inodorus (Tabela 3). Nas diferentes doses de $\mathrm{N}$ e K utilizadas por Fernandes et al. (2003), em média foram encontrados 4,4 $\mathrm{g} \mathrm{Kg}^{-1}$ de Mg nas folhas de meloeiro, teores inferiores aos encontrados nos tratamentos deste trabalho.

As médias de teores de Ca e Mg em g Kg de matéria seca-1 encontradas por Duenhas et al. (2004) nos tecidos vegetais aos 30, 45 e 60 dias após a emergência de plantas de melão, foram inferiores aos encontrados neste trabalho. Cabe ressaltar que os valores de $\mathrm{N}, \mathrm{P}, \mathrm{K}, \mathrm{Ca}$ e também $\mathrm{Mg}$ podem sofrer influência de vários fatores como condições de solo, clima e variedades, segundo Malavolta et al. (1997). 
Dentre estes três macronutrientes analisados, o cálcio apresentou os maiores teores extraídos pela planta, com respectivamente 57,02; 55,72 e 54,50 $\mathrm{g} \mathrm{Ca} \mathrm{Kg}^{-1}$ de massa seca dos tratamentos A, B e C, seguido do magnésio, com 13,38; 13,37 e 12,83 g Mg. $\mathrm{Kg}^{-1}$ de massa seca dos tratamentos $\mathrm{A}$, C e B respectivamente (Tabela 3).

Analisando a Tabela 3, a análise de variância não revelou efeito significativo $(P<0,05)$ entre os tratamentos analisados para teores médios de cálcio e magnésio encontrados na parte aérea do meloeiro. Os teores de enxofre extraído pelas plantas do meloeiro foram estatisticamente maiores nos tratamentos B e C (2,74 e 3,50 g S. $\mathrm{Kg}^{-1}$ de massa seca), teores estes, significativamente diferentes dos apresentados pelos tratamentos A e B (1,96 e 2,74 g S. $\mathrm{Kg}^{-1}$ de massa seca) (Tabela 3).

Ainda na mesma tabela, nota-se que os teores médios de $S$ encontrados estão muito inferiores aos encontrados por Cañizares et al. (2005) trabalhando com água enriquecida com dióxido de carbono, sendo de 30,1 e $26,6 \mathrm{~g} \mathrm{Kg}^{-1}$ de massa seca para plantas sem enxertia no 1ㅇ e 2 o semestres de experimento respectivamente, e de 28,1 e 15,8 $\mathrm{g} \mathrm{Kg}^{-1}$ de massa seca para plantas com enxertia no 1 으 e 2 ㅇ semestres de experimento respectivamente, dados obtidos aos 63 dias após a após o transplante de plantas de pepino.

\section{CONCLUSÕES}

Os tratamentos não influenciaram significativamente nos teores de $\mathrm{N}, \mathrm{P}, \mathrm{K}, \mathrm{Ca}$ e $\mathrm{Mg}$ da parte aérea das plantas de meloeiro. No que se refere ao teor de $S$, os tratamentos B (NPK 10-28-20) e C (NPK 3-12-6) apresentaram os maiores teores na parte aérea da planta, não diferindo estatisticamente entre si, diferindo apenas dos tratamentos A (NPK 50-25-25) e B (NPK 10-28-20), que tiveram comportamento estatístico semelhante.

\section{REFERÊNCIAS}

BASTOS, T. X.; PACHECO, N. A.. Informativo

Agrometeorológico 1998. Belém: Embrapa Amazônia Oriental, 2001.

BELFORT, C. C.; HAAG, H. P.; MATSUMOTO, T.; CARMELLO, Q. A. C.; SANTOS, J. W. C.. Nutrição mineral de hortaliças. LXX. Acumulação de matéria seca e recrutamento de macronutrientes pelo melão (Cucumis melo L. cV. Valenciano amarelo (AC), cultivado em latossolo amarelo em Presidente Venceslau, SP. Anais da Escola Superior de Agricultura Luiz de Queiroz, v.43, n.1, p.159-218, 1986.

CAÑIZARES, K. A. L.; RODRIGUES, J. D.; GOTO, R.; BÔAS, R. L. V.. Influência da irrigação com água enriquecida com dióxido de carbono e da enxertia sobre o estado nutricional de plantas de pepino. Horticultura Brasileira, Brasília, v.23, n.1, p.9-14, 2005.

CRISÓSTOMO, L. A.; SANTOS A. A.; RAIJ, B. V.; FARIA, C. M. B.; SILVA, D. J.; FERNANDES, F. A. M.; SANTOS, F. J. S.; CRISÓSTOMO, J. R.; FREITAS, J. A. D.; HOLANDA, J. S.; CARDOSO, J. W.; COSTA, N. D.. Adubação, irrigação, híbridos e práticas culturais para o meloeiro no Nordeste. Fortaleza: Embrapa Agroindústria Tropical, 2002.
DUENHAS, L. H.; PINTO, J. M.; GOMES, T. C. A.. Teores de macronutrientes em plantas de melão cultivado em sistema orgânico fertirrigado com substâncias húmicas. In: CONGRESSO BRASILEIRO DE OLERICULTURA, 44. Anais. Campo Grande: Embrapa, 2004.

EMBRAPA. Centro Nacional de Pesquisa de Solos. Manual de métodos de análise de solo. Rio de Janeiro: Embrapa Centro Nacional de Pesquisa de Solos, 1997.

FERNANDES, A. L.; GRASSI FILHO, H.. Manejo da fertirrigação nitrogenada e potássica na cultura do melão rendilhado (Cucumis melo reticulatus Naud). Revista Irriga, Botucatu, v.8, n.3, p.178-190, 2003.

GRANGEIRO, L. C.; CECILIO FILHO, A. B.. Acúmulo e exportação de macronutrientes pelo híbrido de melancia Tide. Horticultura Brasileira, Brasília, v.22, n.1, 2004.

MAIA, C. E.; MORAIS, E. R. C.; PORTO FILHO, F. Q.; GUEYI, H. R.; MEDEIROS, J. F.. Teores foliares de nutrientes em meloeiro irrigado com águas de diferentes salinidades. Revista Brasileira de Engenharia Agrícola e Ambiental. Campina Grande, v.9, p.292-295, 2005. 
MALAVOLTA, E.; VITTI, G. C.; OLIVEIRA, S. A.. Avaliação do

estado nutricional das plantas: princípios e aplicações. 2 ed. Piracicaba: POTAFOS, 1997.

SILVA JUNIOR, M. J.; MEDEIROS, J. F.; OLIVEIRA, F. H. T.; DUTRA, I.. Acúmulo de matéria seca e absorção de nutrientes pelo meloeiro pele-de-sapo. Revista Brasileira de Engenharia Agrícola e Ambiental, Campina Grande, v.10, n.2, p.364-368, 2006.

SILVA, J. R.; MEDEIROS FILHO, S.; HOLANDA, J. S.; MELO F. I. O.. Produção de cultivares de melão em função de adubações corretivas de potássio e magnésio. Revista Ciência Agronômica, v.34, n.2, p.225-231, 2003.
SILVA, S. B.. Análise de solos. Belém: Universidade Federal Rural da Amazônia. 2003.

SOUSA, V. F.; COELHO, E. F.; SOUZA, V. A. B.; HOLANDA FILHO, R. S. F.. Efeitos de doses de nitrogênio e potássio aplicadas por fertirrigação no meloeiro. Rev. Bras. Eng. Agríc. Ambient., v.9, n.2, p.210-214, 2005.

VIDA, J. B.; ZAMBOLIM, L.; TESSMANN, D. J.; BRANDÃO FILHO, J. U. T.; VERZIGNASSI, J. R.; CAIXETA, M. P.. Manejo de doenças de plantas em cultivo protegido. Fitopatologia Brasileira, v.29, p.355-372, 2004.

A CBPC - Companhia Brasileira de Produção Científica (CNPJ: 11.221.422/0001-03) detém os direitos materiais desta publicação. Os direitos referem-se à publicação do trabalho em qualquer parte do mundo, incluindo os direitos às renovações, expansões e disseminações da contribuição, bem como outros direitos subsidiários. Todos os trabalhos publicados eletronicamente poderão posteriormente ser publicados em coletâneas impressas sob coordenação da Sustenere Publishing, da Companhia Brasileira de Produção Científica e seus parceiros autorizados. Os (as) autores (as) preservam os direitos autorais, mas não têm permissão para a publicação da contribuição em outro meio, impresso ou digital, em português ou em tradução. 